\title{
Chronic respiratory disease morbidity in construction workers: patterns and prognostic significance for permanent disability and overall mortality
}

\author{
D. Rothenbacher*, V. Arndt*+, E. Fraisse+, U. Daniel**, T.M. Fliedner+, H. Brenner*
}

Chronic respiratory disease morbidity in construction workers: patterns and prognostic significance for permanent disability and overall mortality. D. Rotherbacher, V. Arndt, E. Fraisse, U. Daniel, T.M. Fliedner, H. Brenner. @ERS Journals Ltd 1997.

ABSTRACT: The aim of this study was to determine chronic respiratory disease morbidity in construction workers, and to assess the prognostic value of various morbidity measures on permanent disability and on all-cause mortality.

Subjects in this analysis were male employees in the German construction industry, aged 40-64 yrs, who were examined by the occupational health service between August 1986 and December 1988. Prevalence of respiratory disorders as characterized by: 1) pathological findings on lung auscultation; 2) reduced forced expiratory volume in one second (FEV1); and 3) a medical diagnosis of chronic respiratory disease (International Classification of Diseases 9th revision (ICD-9) 490-496) was assessed among occupational groups of construction workers, and compared with prevalence among white-collar employees. Active follow-up was conducted between October 1992 and July 1994 to ascertain working and life status (completeness: 92 and $96 \%$, respectively). The prognostic value of the morbidity measures on permanent disability and on allcause mortality was assessed using the Cox proportional hazards model.

In the entire cohort, crude prevalence was $7.6 \%$ for pathological findings on lung auscultation, $8.8 \%$ for a reduced FEV1 ( $<70 \%$ of predicted value), and $6.1 \%$ for a recorded diagnosis of chronic respiratory disease. There was strong variation of prevalence with age, smoking status and, less clearly, occupation. The relative risk for permanent disability varied between 1.9 and 3.2, and for mortality between 2.0 and 2.9 , respectively, when men with the various measures of bronchopulmonary disorders were compared with other men.

The morbidity measures utilized allow the identification of employees at higher risk of disability and death, and this may facilitate targeting of specific prevention and rehabilitation measures.

Eur Respir J 1997; 10: 1093-1099.
*Dept of Epidemiology, and +Institute of Occupational and Social Medicine, University of Ulm, Ulm, Germany. **Occupational Health Service of the Workmen's Compensation Board for Construction Workers, Wuerttemberg, Boeblingen, Germany.

Correspondence: D. Rothenbacher Dept of Epidemiology

University of Ulm D-89069 Ulm Germany

Keywords: Cigarette smoking construction workers early retirement mortality occupational diseases respiratory tract diseases

Received: April 181996 Accepted after revision January 151997

This study was funded by the Association of the Workmen's Compensation Board for Construction Workers, Germany.
According to national mortality statistics, pulmonary diseases rank third as a cause of death after cardiovascular and malignant diseases. Chronic obstructive pulmonary disease (COPD) accounts for more than $50 \%$ of these pulmonary diseases [1]. In addition to its impact on mortality [2], COPD has also been shown to reduce quality of life [3].

Several occupational studies [4-8] have shown an association between chronic pulmonary diseases and exposure to dust, gas or fumes. Construction workers are exposed to a wide range of substances that are potentially hazardous to the respiratory system, including cement dust, wood dust from sawing, dust from the ground, dust from using pneumatic tools on concrete or other stone work, fumes from welding, roofing or paving, and diesel exhaust from machines [9]. In addition, construction workers might be exposed to climatic influences and personal lifestyle factors, such as cigarette smoking, which have also been identified as aetiological factors of COPD [10].
So far, very little is known about the patterns of COPD morbidity in the various professional groups of the construction industry. An occupational study from the United States on 118 construction painters indicated that painters may be at increased risk of developing airflow obstruction, and that these changes may be related to years of exposure and be independent of cigarette smoking [11].

Furthermore, the prognostic significance of the various pulmonary morbidity measures for permanent disability and mortality has not been clearly evaluated. Knowledge of this prognostic significance, however, would facilitate identification of persons at high risk for permanent disability or death, who might benefit most from secondary prevention programmes that could be tailored to individual life style factors as well as to work-related characteristics.

The objective of the present study was to describe the prevalence of chronic respiratory disease in various professions of the construction industry, according to: 
1) pathological findings on lung auscultation; 2) a pathological lung function measure; and 3) a diagnosis of chronic respiratory disease as recorded in the occupational health record of the employees. In addition, we investigated the prognostic significance of these three morbidity measures for early retirement due to disability and all-cause mortality by means of active follow-up.

\section{Materials and methods}

\section{Design and study population}

In the German construction industry, all employees are periodically invited to occupational health examinations by the medical health service of the Workmen's Compensation Board. A cohort study was conducted among construction workers who had undergone occupational health examinations in six occupational health centres of the Workmen's Compensation Board for construction workers in Wuerttemberg (in the South of Germany) between August 1986 and December 1988. In the period of investigation, about $78 \%$ of the employees invited agreed to participate in the examinations.

The present study includes employees aged 40-65 yrs and working as plumbers, carpenters, painters or varnishers, plasterers, bricklayers, unskilled workers, or as office employees, engineers or architects. The latter three professions were combined in a common group ("white-collar employees"). In total, 4,958 men met the inclusion criteria for this study.

\section{Data collection}

Baseline examination. The medical examination at baseline consisted of an occupational and medical history, a physical examination, and blood and serum analysis. In addition, audiogram and pulmonary function tests were performed, and electrocardiography or chest radiography, if necessary. The examinations were conducted by experienced occupational health physicians, according to a standardized documentation protocol, considering all aspects of a complete medical history and physical examination.

Three different measures were used to characterize bronchopulmonary morbidity at baseline: 1) pathological findings on lung auscultation (rales, rhonchi or crackling, or a prolonged duration of expiration); 2) reduced forced expiratory volume during one second (FEV1) as percentage of the predicted height-, weight- and agecorrected sex-specific value [12] (grading of pulmonary impairment: following the staging system proposed by the European Respiratory Society [13]); and 3) a recorded medical diagnosis related to chronic respiratory disease (International Classification of Diseases 9th Revision (ICD-9) 490-496, COPD) in the health record of the employees. This recorded diagnosis integrates the medical history (including information from other medical institutions the employee may have consulted in the past) as well as the results of the examination at the occupational health service.

In contrast to the other measures, FEV1 was available in only $77.3 \%$ of employees. Completeness of this measurement varied according mainly to location of the health centre (from 98 to 67\%). This was also the case for smoking history, which, in total, was recorded for only $76 \%$ of the employees.

Follow-up. Active follow-up was carried out to ascertain whether early retirement due to permanent disability or death had occurred after the baseline examination. Therefore, employers and employees or their relatives were recontacted between October 1992 and July 1994. If necessary, information on life status was completed by the German system of population registries.

\section{Statistical analysis}

Cross-sectional part of the study. In the cross-sectional part of the study (analysis of the baseline examinations), the crude prevalence for the various morbidity measures was calculated for each of the occupational groups and for each 5 year age group, according to smoking status. Furthermore, we assessed the independent association of occupation and smoking status with the prevalence of the various morbidity measures after controlling for several potential confounders, including age, nationality, company size, and occupational health centre, by means of multivariate statistical modelling. Therefore, Breslow's modification of Cox's model was used to estimate the prevalence rate ratios (PRR) from cross-sectional data, as described by LEE [14].

Follow-up part of the study. In the follow-up part of the study, which was performed to quantify the prognostic value of the various morbidity measures on permanent disability and mortality, crude rates for permanent disability and all-cause mortality were calculated for individuals with and without the respective morbidity measure of interest. In addition, the association of the various morbidity measures with the occurrence of permanent disability and with all-cause mortality was assessed using the proportional hazards model according to Cox, adjusting for age, occupation, nationality, smoking status, company size and health centre. In addition, to assess the independent effect of each morbidity measure, all three measures were included in one model after adjustment for the covariates. The proportional hazard assumption was checked by inclusion of time-dependent variables in the models. All statistical procedures were conducted with the Statistical Analysis System (SAS) software package [15].

\section{Results}

As shown in table 1, the number of participants in the occupational groups varied between 207 (whitecollar) and 1,861 (bricklayers). Mean age ranged 48 yrs (plumbers) to $51 \mathrm{yrs}$ (carpenters). Average length of employment in the construction industry ranged 26.2 yrs (unskilled workers) to 32.0 yrs (plasterers). The proportion of foreign workers was highest in the group of unskilled workers (58\%) and lowest in the white-collar employees $(2 \%)$. The smoking history varied considerably among the various professions. At the time of the baseline examination, only $41 \%$ of white-collar employees reported being current smokers, compared to $63 \%$ of unskilled workers. The mean number of cigarettes smoked 
Table 1. - Characteristics of the study population according to profession: number, mean age, nationality, smoking status, and mean number of cigarettes smoked by current smokers

\begin{tabular}{|c|c|c|c|c|c|c|c|}
\hline & \multicolumn{7}{|c|}{ Profession } \\
\hline & $\begin{array}{l}\text { White-collar } \\
\text { employees }\end{array}$ & Plumbers & Carpenters & $\begin{array}{c}\text { Painters/ } \\
\text { varnishers }\end{array}$ & Plasterers & $\begin{array}{l}\text { Unskilled } \\
\text { workers }\end{array}$ & Bricklayers \\
\hline Subjects $\mathrm{n}$ & 207 & 388 & 521 & 633 & 544 & 804 & 1861 \\
\hline Age $\mathrm{yrs}^{\#}$ & $50(6)$ & $48(5)$ & $51(6)$ & 49 (5) & $50(5)$ & $50(6)$ & $50(5)$ \\
\hline $\begin{array}{l}\text { Length of } \\
\text { employment yrs }\end{array}$ & $28.0(7.9)$ & $29.5(6.9)$ & $31.6(8.0)$ & 31.7 (7.5) & $32.0(7.3)$ & $26.2(8.6)$ & 29.8 (7.9) \\
\hline Foreign workers $\%$ & 2 & 6 & 25 & 13 & 16 & 58 & 3 \\
\hline Smoking history $\%$ & & & & & & & \\
\hline Never & 38 & 20 & 26 & 16 & 15 & 20 & 19 \\
\hline Former & 21 & 29 & 25 & 28 & 29 & 17 & 26 \\
\hline Current & 41 & 51 & 48 & 56 & 56 & 63 & 54 \\
\hline $\begin{array}{l}\text { Current smoking } \\
\text { cigarettes } \text { day }^{-1 \ddagger}\end{array}$ & 20.0 & 19.4 & 18.7 & 19.5 & 21.3 & 19.5 & 20.8 \\
\hline
\end{tabular}

\#: Mean and SD in parenthesis; $\ddagger$ : mean.

per day by current smokers ranged 18.7 (carpenters) to 21.3 (plasterers).

Life status and employment status at follow-up could be ascertained for $96 \%$ and $92 \%$ of participants, respectively. In general, completeness of follow-up was higher in employees with German nationality ( $97 \%$ for mortality and $94 \%$ for disability) than in employees with foreign nationality ( $92 \%$ for mortality and $86 \%$ for disability) because of migration of foreign employees. The mean follow-up time was 4.4 yrs for employment status and 4.6 yrs for life status. In the period of follow-up, 340 employees were granted a disability pension for healthrelated reasons, and 141 employees died. Information regarding the reason (medical diagnosis) for permanent disability was available in 59\% of disability cases. Main reasons for early retirement due to permanent disability were: disorders of the musculoskeletal system (40\%); diseases of the cardiovascular system (24\%); psychiatric disorders (8\%); and respiratory diseases $(6 \%)$.
The crude prevalence of bronchopulmonary disorders at baseline, according to the various health measures, is presented in table 2. Prevalence of pathological findings on lung auscultation (rales, rhonchi or crackling, or a prolonged duration of expiration) ranged $2.9 \%$ (whitecollar employees) to $12.6 \%$ (unskilled workers). Prevalence of a reduced FEV1 ( $<70 \%$ of pred) ranged $4.5 \%$ (white-collar employees) to $12.9 \%$ (unskilled workers). A diagnosis of chronic respiratory diseases (ICD-9 490496) in the health record of the employees was recorded between $3.0 \%$ (white-collar employees) and 9.1\% (unskilled workers). In general, in most occupational groups, measurement of a reduced FEV $1<70 \%$ pred was more common than recording of pathological findings on lung auscultation or a medical diagnosis related to chronic respiratory disease. The crude prevalence of all three morbidity measures was highest in current smokers. Among the current smokers, however, the group of white-collar employees showed the lowest prevalence.

Table 2. - Crude prevalence of the various respiratory morbidity measures by occupation and smoking status

\begin{tabular}{|c|c|c|c|c|c|c|c|c|}
\hline & \multicolumn{8}{|c|}{ Profession } \\
\hline & $\begin{array}{c}\text { White-collar } \\
\qquad(\mathrm{n}=207)\end{array}$ & $\begin{array}{l}\text { Plumbers } \\
(\mathrm{n}=388)\end{array}$ & $\begin{array}{c}\text { Carpenters } \\
(\mathrm{n}=521)\end{array}$ & $\begin{array}{l}\text { Painters/ } \\
\text { varnishers } \\
(\mathrm{n}=633)\end{array}$ & $\begin{array}{l}\text { Plasterers } \\
(\mathrm{n}=544)\end{array}$ & $\begin{array}{l}\text { Unskilled } \\
\text { workers } \\
(\mathrm{n}=804)\end{array}$ & $\begin{array}{l}\text { Bricklayers } \\
(\mathrm{n}=1861)\end{array}$ & $\begin{array}{c}\text { Total } \\
(\mathrm{n}=4958)\end{array}$ \\
\hline \multicolumn{9}{|c|}{ Pathological findings on lung auscultations \% } \\
\hline Lifelong NS & 3.5 & 5.5 & 5.0 & 2.6 & 5.1 & 6.4 & 3.6 & 4.3 \\
\hline Ex-smoker & 0.0 & 3.8 & 6.3 & 2.3 & 6.8 & 15.3 & 6.4 & 6.5 \\
\hline Current smoker & 6.7 & 9.9 & 17.5 & 7.0 & 11.7 & 15.3 & 11.6 & 12.0 \\
\hline Unknown & 0.0 & 1.8 & 1.4 & 0.0 & 3.5 & 8.6 & 2.6 & 2.9 \\
\hline Total & 2.9 & 5.7 & 8.6 & 3.8 & 7.7 & 12.6 & 7.3 & 7.6 \\
\hline \multicolumn{9}{|c|}{ FEV1 $<70 \%$ pred } \\
\hline Lifelong NS & 6.1 & 2.3 & 10.8 & 10.8 & 0.0 & 7.6 & 6.3 & 6.7 \\
\hline Ex-smoker & 13.1 & 6.7 & 9.1 & 4.5 & 5.7 & 14.7 & 9.2 & 8.7 \\
\hline Current & 2.2 & 8.6 & 12.7 & 12.4 & 11.6 & 13.7 & 10.7 & 11.4 \\
\hline Unknown & 0.0 & 0.0 & 5.7 & 3.5 & 4.0 & 14.3 & 4.6 & 5.2 \\
\hline Total & 4.5 & 5.2 & 9.9 & 8.5 & 6.9 & 12.9 & 8.4 & 8.8 \\
\hline \multicolumn{9}{|c|}{ COPD (ICD-9 490-496) \% } \\
\hline Lifelong NS & 3.5 & 5.5 & 5.0 & 1.3 & 5.1 & 4.0 & 1.8 & 3.2 \\
\hline Ex-smoker & 3.2 & 2.4 & 8.4 & 4.6 & 5.1 & 7.2 & 5.3 & 5.4 \\
\hline Current smoker & 3.3 & 9.2 & 11.5 & 7.8 & 13.0 & 12.6 & 7.9 & 9.6 \\
\hline Unknown & 1.7 & 0.0 & 1.4 & 0.8 & 2.8 & 5.6 & 2.6 & 2.7 \\
\hline Total & 3.0 & 4.4 & 6.9 & 5.2 & 7.7 & 9.1 & 5.3 & 6.1 \\
\hline
\end{tabular}

NS: nonsmoker; FEV1: forced expiratory volume in one second; \% pred: percentage of predicted value; COPD: chronic obstructive pulmonary disease; ICD-9: International Classification of Diseases 9th revision. 
Table 3. - Prevalence of the various pulmonary morbidity measures by age and smoking status

\begin{tabular}{|c|c|c|c|c|c|}
\hline & \multicolumn{5}{|c|}{ Age yrs } \\
\hline & $\begin{array}{c}40-44 \\
(n=928)\end{array}$ & $\begin{array}{c}45-49 \\
(n=1393)\end{array}$ & $\begin{array}{c}50-54 \\
(n=1512)\end{array}$ & $\begin{array}{l}55-59 \\
(\mathrm{n}=963)\end{array}$ & $\begin{array}{c}60-64 \\
(n=162)\end{array}$ \\
\hline \multicolumn{6}{|c|}{ Pathological findings on lung auscultation \% } \\
\hline Lifelong NS & 2.4 & 3.4 & 3.0 & 9.8 & 0.0 \\
\hline Ex-smoker & 2.6 & 6.2 & 6.6 & 8.8 & 8.5 \\
\hline Current smoker & 9.3 & 9.1 & 11.3 & 20.6 & 20.5 \\
\hline Unknown & 1.1 & 3.6 & 2.5 & 2.0 & 12.5 \\
\hline Total & 5.9 & 6.6 & 6.9 & 11.4 & 11.8 \\
\hline \multicolumn{6}{|c|}{ FEV1 $<70 \%$ pred } \\
\hline Lifelong NS & 2.8 & 3.3 & 6.4 & 15.2 & 5.0 \\
\hline Ex-smoker & 3.3 & 7.5 & 8.2 & 14.0 & 10.0 \\
\hline Current smoker & 7.7 & 9.4 & 14.3 & 14.1 & 23.5 \\
\hline Unknown & 4.2 & 4.8 & 6.1 & 3.9 & 10.0 \\
\hline Total & 5.7 & 7.2 & 9.7 & 11.9 & 12.9 \\
\hline \multicolumn{6}{|c|}{ COPD (ICD-9 490-496) \% } \\
\hline Lifelong NS & 1.6 & 2.9 & 2.6 & 6.1 & 0.0 \\
\hline Ex-smoker & 2.0 & 4.1 & 6.6 & 6.5 & 10.6 \\
\hline Current smoker & 7.4 & 8.0 & 9.6 & 14.9 & 14.3 \\
\hline Unknown & 1.1 & 2.6 & 2.7 & 3.6 & 4.4 \\
\hline Total & 4.5 & 5.4 & 6.1 & 8.6 & 8.0 \\
\hline
\end{tabular}

For definitions see legend to table 2 .

Prevalence of the various findings by age and smoking status is presented in table 3 . In total, prevalence both of pathological findings on lung auscultation and reduced FEV1 showed a monotonic increase with age. The prevalence of a diagnosis related to chronic respiratory disease had a peak in the 55-59 yrs age group. In the 60-64 yrs age group, prevalence was slightly lower than in the 55-59 yrs age group. However, the small sample size in this age group $(n=162)$ has to be considered. Again, among the current smokers, prevalence of each morbidity measure was highest in the various age categories when compared with the other smoking categories.

Table 4 shows the prevalence rate ratios (PRR) for the various morbidity measures for each professional group. With regard to the pathological findings on lung auscultation, blue-collar professions had an elevated PRR, which ranged 1.3 (painters/varnishers) to 2.1 (unskilled workers), but elevations were not statistically significant, since the $95 \%$ confidence interval $(95 \% \mathrm{CI})$ included one. Likewise, no statistically significant excess morbidity in terms of a reduced FEV1 or a diagnosis related to COPD was evident in the different occupations when compared with the reference group (white-collar employees). However, there was a tendency towards elevated PRR for all occupations when compared with the white-collar employees. There was a strong association of all morbidity measures with smoking status. Associations were higher for findings on lung auscultation and a recorded diagnosis of COPD than for FEV1 $<70 \%$ pred.
Table 4. - Prevalence rate ratio (PRR) and 95\% confidence interval $(95 \% \mathrm{Cl})$ of the various pulmonary morbidity measures by occupation and smoking status

\begin{tabular}{|c|c|c|c|}
\hline \multirow[t]{2}{*}{ Occupation } & \multicolumn{3}{|c|}{ Morbidity measure } \\
\hline & $\begin{array}{c}\text { Pathological } \\
\text { findings on lung } \\
\text { auscultation PRR } \\
(95 \% \mathrm{CI})\end{array}$ & $\begin{array}{c}\text { FEV1 } \\
<70 \% \text { pred } \\
\mathrm{PRR}^{\#} \\
(95 \% \mathrm{CI})\end{array}$ & $\begin{array}{c}\text { COPD } \\
\text { (ICD-9 490-496 } \\
\text { PRR }^{\#} \\
(95 \% \text { CI })\end{array}$ \\
\hline \multicolumn{4}{|l|}{ Profession } \\
\hline White-collar & 1 & 1 & 1 \\
\hline Plumbers & $1.7(0.7-4.2)$ & $1.2(0.5$ & $1.9(0.7-5.1)$ \\
\hline Carpenters & $1.9(0.8-4.4)$ & $1.6(0.7-3.5)$ & $1.8(0.7-4.6)$ \\
\hline $\begin{array}{l}\text { Painters/ } \\
\text { varnishers }\end{array}$ & $1.3(0.5-3.1)$ & $1.5(0.7-3.3)$ & $1.9(0.7-4.8)$ \\
\hline Plasterers & $1.8(0.8-4.4)$ & $1.2(0.5$ & $2.4(0.9-6.1$ \\
\hline $\begin{array}{l}\text { Unskilled } \\
\text { workers }\end{array}$ & $2.1(0.9-4.8)$ & $1.6(0.7-3.6)$ & $1.7(0.7-4.4)$ \\
\hline Bricklayers & $1.6(0.7-3.7)$ & $1.4(0.7-3.1)$ & $1.3(0.5-3.3)$ \\
\hline \multicolumn{4}{|c|}{ Smoking status } \\
\hline Lifelong NS & 1 & 1 & 1 \\
\hline kers & & $(1.0$ & $1.6-4.3)$ \\
\hline Current & $3.8(2.6-5.5)$ & $2.1(1.5-2.9)$ & $4.5(2.9-7.0)$ \\
\hline
\end{tabular}

smokers

\#: model includes profession and smoking status and is adjusted for age, nationality, company size, and health centre; $¥$ : reference group. For definitions see legend to table 2 .

The number of events (early retirement due to permanent disability and death, respectively), the crude rate and the relative risk (RR) of permanent disability and death in the follow-up period are presented in table 5. The RR both for permanent disability and mortality ranged 1.93.2 and 2.0-2.9, respectively, after adjustment for age, occupation, nationality, company size and health centre, when workers with the various measures of bronchopulmonary disorders were compared with healthy workers. The RR for subjects with a FEV $1 \leq 69 \%$ pred was 3.2 for disability and 2.9 for mortality, compared with men with a FEV 1 of $\geq 100 \%$ pred.

However, when all three morbidity measures were included in one model simultaneously (table 6), the measures "pathological findings on lung auscultation" and the categorized FEV1 measure showed an independent association with both end-points (disability and mortality), whereas a recorded diagnosis of COPD did not.
Table 5. - Relative risk (RR) and $95 \%$ confidence interval $(95 \% \mathrm{Cl})$ for the occurrence of disability and mortality in the follow-up period as evaluated with each morbidity measure

\begin{tabular}{|c|c|c|c|c|c|c|c|}
\hline & \multicolumn{2}{|c|}{$\begin{array}{l}\text { Pathological findings } \\
\text { on lung auscultation }\end{array}$} & \multicolumn{3}{|c|}{$\begin{array}{l}\text { FEV } 1 \\
\% \text { pred }\end{array}$} & \multicolumn{2}{|c|}{$\begin{array}{l}\text { Recorded diagnosis } \\
\text { of COPD }\end{array}$} \\
\hline & Yes & No & $\leq 69$ & 70-99 & $\geq 100$ & Yes & No \\
\hline Disability & & & & & & & \\
\hline Person-years & 2460 & 17582 & 1167 & 7145 & 7162 & 1500 & 18694 \\
\hline Events n & 88 & 250 & 47 & 124 & 81 & 57 & 283 \\
\hline Crude rate* & 3578 & 1422 & 4027 & 1735 & 1131 & 3785 & 1514 \\
\hline $\begin{array}{l}\text { Relative risk }{ }^{\ddagger} \\
(95 \% \text { CI })\end{array}$ & $\begin{array}{c}2.1 \\
(1.6-2.7)\end{array}$ & $1^{\#}$ & $\begin{array}{r}3.2 \\
(1.8-5.6\end{array}$ & 6) $\begin{array}{c}1.7 \\
(1.1-2.6\end{array}$ & 6) & $\begin{array}{c}1.9 \\
(1.4-2.6)\end{array}$ & $1^{\#}$ \\
\hline Mortality & & & & & & & \\
\hline Person-years & 2896 & 19051 & 1371 & 7852 & 7718 & 1778 & 20340 \\
\hline Events n & 38 & 100 & 19 & 60 & 34 & 24 & 117 \\
\hline Crude rate* & 1312 & 525 & 1386 & 764 & 441 & 1350 & 575 \\
\hline $\begin{array}{l}\text { Relative risk }{ }^{\ddagger} \\
(95 \% \text { CI })\end{array}$ & $\begin{array}{c}2.2 \\
(1.5-3.2)\end{array}$ & $1^{\#}$ & $\begin{array}{c}2.9 \\
(2.0-4.2\end{array}$ & 2) $\begin{array}{c}1.4 \\
(1.1-1.9)\end{array}$ & $1^{\#}$ & $\begin{array}{c}2.0 \\
(1.3-3.1)\end{array}$ & $1^{\#}$ \\
\hline
\end{tabular}

*: events (disability, death) per 100,000 person-years; $¥$ : adjusted for age, occupation, nationality, company size; \#: reference category. For definitions see legend to table 2. 
Table 6. - Relative risk (RR) and 95\% confidence interval $(95 \% \mathrm{Cl})$ for the occurrence of disability and mortality in the follow-up period as evaluated with all three morbidity measures in one model

\begin{tabular}{lcc}
\hline Morbidity measure* & $\begin{array}{c}\text { Disability } \\
\mathrm{RR}^{\ddagger}(95 \% \mathrm{CI})\end{array}$ & $\begin{array}{c}\text { Mortality } \\
\mathrm{RR}\end{array}$ (95\% CI) \\
\hline $\begin{array}{l}\text { Pathological findings } \\
\text { on lung auscultation }\end{array}$ & $1.7(1.1-2.6)$ & $2.0(1.1-3.6)$ \\
FEV1 \% pred & & \\
$\geq 100$ & $1^{*}$ & $1^{*}$ \\
$\geq 70-<100$ & $1.4(1.0-1.8)$ & $1.6(1.1-2.5)$ \\
$\leq 69$ & $2.5(1.7-3.0)$ & $2.3(1.2-4.3)$ \\
COPD (ICD-9 & $0.9(0.5-1.4)$ & $1.3(0.7-2.5)$ \\
$460-469)$ & &
\end{tabular}

*: reference category: absence of the respective measure, or, for FEV1 subjects with a value $\geq 100 \%$ pred; $\$$ : adjusted for age, occupation, nationality, company size. For definitions see legend to table 2 .

\section{Discussion}

In the present study, the prevalence and patterns of chronic respiratory disease were assessed in workers in the construction industry. A tendency towards elevated prevalence was seen in most occupations of the construction industry, when compared with white-collar employees, although increased prevalence rates were not statistically significant. There was, however, a clear excess morbidity related to smoking status. In addition, this study demonstrated that all three morbidity measures investigated are related to the occurrence of early retirement due to permanent disability and death during the follow-up period. When considered together, pathological findings on lung auscultation and the result of the lung function test (FEV1) were independent predictors of both end-points, permanent disability and mortality, whereas a recorded diagnosis of COPD was not.

Pathological findings on lung auscultation, as defined in this study, are probably related to chronic obstructive diseases. Findings on lung auscultation caused by acute respiratory infections should be rare in this population because, in general, employees with such diseases do not come to the attention of the occupational health physician. In Germany, the occupational health service is not involved in the diagnosis and treatment of acute health events.

The results of the cross-sectional part of this study are in agreement with another study conducted in the German construction industry in 1984 [16]. It reported similar prevalence of findings regarding chronic morbidity measures in the various professional groups of construction workers, as characterized by means of clinical examination and pulmonary function tests. An occupational study from Canada conducted in construction insulators also demonstrated an excess prevalence of airflow obstruction as measured by lung function test [17].

Asthma due to occupational exposure is described in painters and varnishers in the construction industry. A significant relationship between years of exposure to paint products and airflow obstruction has been demonstrated in construction painters when compared to sheet metal workers. For every year of exposure, a decline in FEV1 of $11 \mathrm{~mL}$ was estimated [11, 18].
In the present whole study population, immunogenic disorders of the lung accounted for only a very small proportion of the chronic obstructive diseases. Of the recorded COPD diagnoses (ICD 490-496) 4.3\% were due to asthma (ICD 493) or exogen allergic alveolitis (ICD 495). This minor role of immunogenic disorders is further reflected by the fact, that in the German construction industry, allergic intrinsic or extrinsic obstructive diseases account for only a small percentage of the occupational respiratory diseases, as evident in the 24 cases of compensated work-related occupational illnesses due to asthma and exogenous allergic alveolitis in 1993 [19].

According to the spirometric results of the present study population, up to $14 \%$ (e.g. age group 60-64 yrs) may have suffered signs of moderate or severe chronic respiratory disease. Pulmonary morbidity was clearly related to smoking status. Furthermore, there was a tendency towards a job-specific elevation when comparing bluecollar employees with the white-collar employees, but results did not reach statistical significance, due to the limited sample size and resulting lack of power. Furthermore, by using job title as a proxy measure for a broad range of occupational exposures, the health effects of specific exposures may have been missed. Specific measures of dust or other agents may have led to a stronger relationship with the morbidity measures employed. However, this information was not available.

A community-based study in Norway indicated that socioeconomic status, in terms of educational level, is a risk factor for respiratory disorders independent of smoking and airborne exposure [20]. Therefore, the excess morbidity of the unskilled workers compared to the white-collar employees may have been due not only to occupational exposure but also, in part, to differences in environmental factors and personal behaviour. It has been shown, however, that unskilled workers in the construction industry, in particular, face a wide range of hazardous exposures at the workplace, and show widespread adverse health effects [21]. Altogether, however, smoking status was by far the most important risk factor for all morbidity measures investigated in the present study.

The results of the follow-up study, investigating the prognostic value of the three morbidity measures on disability and mortality, revealed that all three are related to the occurrence of health-related disability and death. However, their ability to predict these two outcomes was not independent of each other, as evaluated if all three were included in one model. The diagnosis had no additional predictive ability compared to clinical findings and the result of the lung function test. This is plausible, since the diagnosis is an integrative measure of both, and an association for the given outcomes is lost if the intermediate variable is included in the model.

Overall, the follow-up results are in concordance with several population-based studies that documented the association of an impaired performance in the respiratory function test, respiratory symptoms, or a diagnosis of chronic bronchitis and an increased mortality [22-27]. Furthermore, a positive association between chronic bronchitis and disability has been found in a populationbased follow-up study [28]. A previous study from Germany [29] also reported that respiratory tract ailments were found several years before early retirement due to permanent disability, or premature death. 
In other studies, the strong predictive association between ventilatory impairment and all-cause mortality was reported to be due mainly to circulatory diseases and neoplasms [30], or mortality from respiratory and cardiovascular diseases [31]. Unfortunately, in the present study we had no information regarding cause of death.

A number of limitations have to be considered when evaluating these results. Firstly, the study is based on analysis of a routinely performed examination conducted by a large number of occupational health physicians. Despite standardized documentation, there remains some possibility for subjective judgement, especially regarding the abnormal clinical findings on lung auscultation. Reliability of this measure seems to be rather limited [32]. In addition, the diagnostic criteria for COPD may not be the same in all participating health centres. However, this potential misclassification would most likely have diluted rather than increased the observed associations. Other limitations include selection mechanisms of workers for inclusion in the study. A problem inherent in all prevalence studies is that workers with the disease, possibly aggravated by a job-related exposure, may change jobs. This potential healthy worker effect might also have led to some underestimation of excess morbidity among construction workers compared with whitecollar employees.

Furthermore, information on smoking and results of lung functions test were not collected in all employees. Lack of information, however, was strongly associated with the location of the health centre and not with profession or other personal factors; therefore, the introduction of selection bias seems unlikely. Regarding the cross-sectional part of the study, the size of the reference group was comparatively small, but it reflects the proportion of white-collar employees to blue-collar workers in the construction industry, especially in small companies.

Despite these limitations, this study reveals morbidity patterns of chronic respiratory diseases in the construction industry and gives an indication that, in addition to possible occupational factors, smoking contributes most to the prevalence described. Furthermore, the study demonstrates the predictive value of the morbidity measurements used on permanent disability and all-cause mortality. These measures may, therefore, help to identify employees at high risk, who might benefit most from secondary prevention measures. Such measures may be targeted on the behaviour of the individuals, the work environment, and on rehabilitation measures.

\section{References}

1. Statistisches Bundesamt, ed. Reihe 4. Todesursachen. Fachserie 12: Gesundheitswesen. Wiesbaden, Metzler and Poeschel, 1992.

2. Morgan WK. On dust, disability and death. Am Rev Respir Dis 1986; 134: 639-641.

3. Foxman B, Sloss EM, Lohr KN, Brook RH. Chronic bronchitis: prevalence, smoking habits, impact, and antismoking advice. Prev Med 1986; 15: 624-631.

4. Costello J, Castellan RM, Swecker GS, Kullman GJ. Mortality of a cohort of US workers employed in the crushed stone industry 1940-1980. Am J Ind Med 1995; 27: 625-640.
5. Korn RJ, Dockery DW, Speizer FE, Ware JH, Ferris BG. Occupational exposures and chronic respiratory symptoms: a population-based study. Am Rev Respir Dis 1987; 136: 296-304.

6. Heedrik D, Pouwels H, Kromhout H, Kromhout D. Chronic nonspecific lung disease and occupational exposure estimated by means of a job exposure matrix: the Zutphen study. Int J Epidemiol 1989; 18: 29-38.

7. Bakke P, Eide GE, Hanoa R, Gulsvik A. Occupational dust or gas exposure and prevalence of respiratory symptoms and asthma in a general population. Eur Respir $J$ 1991; 4: 27-38.

8. Viegi G, Carrozi L, Di Pede F, et al. Risk factors for chronic obstructive pulmonary disease in a north Italian rural area. Eur J Epidemiol 1994; 10: 725-731.

9. Ringen K, Seegal J, Englund A. Safety and health in the construction industry. Annu Rev Public Health 1995; 16: $165-188$.

10. WHO Expert Committee. Identification and control of work-related diseases: report of the WHO Expert Committee. In: WHO, Ed. Technical Report Series, No. 174, Geneva; WHO, 1985.

11. Schwartz DA, Baker EL. Respiratory illness in the construction industry: airflow obstruction among painters. Chest 1988; 93: 134-137.

12. Quanjer $\mathrm{PhH}$, ed. Standardised lung function testing. Bull Eur Physiopathol Respir 1983; 19 (Suppl. 5): 1-94.

13. Siafakas NM, Vermeire P, Pride NB, et al. on behalf of the Task Force. Optimal assessment and management of chronic obstructive pulmonary disease (COPD). Eur Respir J 1995; 8: 1398-1420.

14. Lee J. Odds ratio or relative risk for cross-sectional data? Int J Epidemiol 1994; 23: 201-203.

15. SAS Institute Inc. SAS language: reference. Version 6, 1st edn. SAS Institute Inc., Cary, NC, USA, 1990.

16. Arbeitsgemeinschaft der Bau-Berufsgenossenschaften, ed. Ergebnis einer arbeitsmedizinischen Untersuchung von 24892 Beschaftigten in der Bauwirtschaft. BauBGPilotstudie 2, Frankfurt/Main, Arbeitsgemeinschaft der Bau-Berufsgenossenschaften, 1984.

17. Kennedy SM, Vedal S, Mueller N, Kassam A, ChanYeung M. Lung function and chest radiograph abnormalities among construction insulators. Am J Ind Med 1991; 20: 673-684.

18. White ML, Baker EL. Measurements of respiratory illness among construction workers. $\mathrm{Br} J$ Ind Med 1988; 45: 523-531.

19. Hauptverband der gewerblichen Berufsgenossenschaften, eds. BK-Dok 93. Dokumentation des BerufskrankheitenGeschehens in der Bundesrepublik Deutschland. Sankt Augustin, Hauptverband der gewerblichen Berufsgenossenschaften, 1995.

20. Bakke PS, Hanoa R, Gulsvik A. Educational level and obstructive lung diseases given smoking habits and occupational airborne exposure: a Norwegian community study. Am J Epidemiol 1995; 141: 1080-1088.

21. Burkhart G, Schulte PA, Robinson C, Sieber WK, Vossenas $\mathrm{P}$, Ringen K. Job tasks, potential exposures, and health risks of laborers employed in the construction industry. Am J Ind Med 1993; 24: 413-425.

22. Higgins MW, Keller JB. Predictors of mortality in the adult population of Tecumseh. Arch Environ Health 1970; 21: 418-424.

23. Sorlie PD, Kannel WB, O'Connor G. Mortality associated with respiratory function and symptoms in advanced age. Am Rev Respir Dis 1989; 140: 379-384.

24. Menotti A, Mariotti S, Seccareccia F, Torsello S, Dima 
F. Determinants of all causes of death in samples of Italian middle-aged men followed up for 25 years. $J$ Epidemiol Commun Health 1987; 41: 243-250.

25. Strachan DP. Ventilatory function, height, and mortality among lifelong nonsmokers. $J$ Epidemiol Commun Health 1992; 46: 66-70.

26. Cook NR, Hebert PR, Satterfield S, Taylor JO, Buring $\mathrm{JE}$, Hennekens $\mathrm{CH}$. Height, lung function, and mortality from cardiovascular disease among elderly. Am J Epidemiol 1994; 139: 1066-1076.

27. Rodriguez BL, Masaki K, Burchfiel C, et al. Pulmonal function decline and 17 year total mortality: the Honolulu heart program. Am J Epidemiol 1994; 140: 398408.

28. Hubert HB, Bloch DA, Fries JF. Risk factors for physical disability in an aging cohort: the NHANES I epidemiologic follow up study. $J$ Rheumatol 1993; 20: 480-488.

29. Biefang S, Gerdes G, Hoeltz J, Potthoff P. Prädiktoren der Frühberentung und gezielte Zuweisung zur medizinischen Rehabilitation. Soz Präventivmed 1990; 35: 129-137.

30. Krzyzanowski M, Wysocki M. The relation of thirteen year mortality to ventilatory impairment and other respiratory symptoms: the Cracow Study. Int J Epidemiol 1986; 15: 56-64.

31. Ebi-Kryston KL. Respiratory symptoms and pulmonary function as predictors of 10 year mortality from respiratory disease, cardiovascular disease, and all-causes in the Whitehall Study. J Clin Epidemiol 1988; 41: 251-260.

32. Brooks D, Thomas J. Interrater reliability of auscultation of breath sounds among physical therapists. Phys Ther 1995; 75: 1082-1088. 